\title{
Effect of Aeration on Yeast Community Structure and Volatile Composition in Uninoculated Chardonnay Wines
}

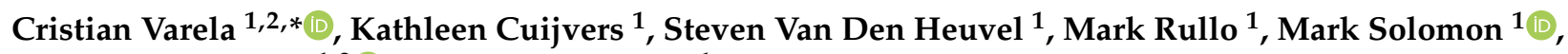 \\ Anthony Borneman 1,2 (D) and Simon Schmidt ${ }^{1}$ \\ 1 The Australian Wine Research Institute, Adelaide, SA 5064, Australia; kate.cuijvers@awri.com.au (K.C.); \\ steven.vandenheuvel@awri.com.au (S.V.D.H.); Mark.Rullo@csiro.au (M.R.); \\ Mark.Solomon@awri.com.au (M.S.); anthony.borneman@awri.com.au (A.B.); \\ simon.schmidt@awri.com.au (S.S.) \\ 2 School of Agriculture, Food \& Wine, Faculty of Sciences, University of Adelaide, Adelaide, SA 5005, Australia \\ * Correspondence: Cristian.Varela@awri.com.au; Tel.: +61-8-8313-6600
}

\section{check for} updates

Citation: Varela, C.; Cuijvers, K.; Van Den Heuvel, S.; Rullo, M.; Solomon,

M.; Borneman, A.; Schmidt, S. Effect of Aeration on Yeast Community Structure and Volatile Composition in Uninoculated Chardonnay Wines Fermentation 2021, 7, 97. https: / /doi.org/10.3390/ fermentation7020097

Academic Editor: Amparo

Gamero Lluna

Received: 26 May 2021

Accepted: 8 June 2021

Published: 11 June 2021

Publisher's Note: MDPI stays neutral with regard to jurisdictional claims in published maps and institutional affiliations.

Copyright: (c) 2021 by the authors. Licensee MDPI, Basel, Switzerland. This article is an open access article distributed under the terms and conditions of the Creative Commons Attribution (CC BY) license (https:// creativecommons.org/licenses/by/ $4.0 /)$.

\begin{abstract}
Uninoculated wines are regarded as having improved mouthfeel and texture and more complex flavor profiles when compared to wines inoculated with commercial S. cerevisiae strains. Uninoculated fermentation involves a complex microbial succession of yeasts and bacteria during fermentation. Microbial population dynamics are affected by several factors that can ultimately determine if a particular species or strain contributes to wine aroma and flavor. In this work, we have studied the effect of aeration, a common winemaking practice, on the yeast microbiota during uninoculated Chardonnay wine fermentation. The timing of aeration and then aeration intensity were evaluated across two successive vintages. While the timing of aeration significantly impacted fermentation efficiency across oxygen treatments, different levels of aeration intensity only differed when compared to the non-aerated control ferments. Air addition increased the viable cell population size of yeast from the genera Hanseniaspora, Lachancea, Metschnikowia and Torulaspora in both vintages. While in 2019, a high relative abundance was found for Hanseniaspora species in aerated ferments, in 2020, T. delbrueckii was visibly more abundant than other species in response to aeration. Accompanying the observed differences in yeast community structure, the chemical profile of the finished wines was also different across the various aeration treatments. However, excessive aeration resulted in elevated concentrations of ethyl acetate and acetic acid, which would likely have a detrimental effect on wine quality. This work demonstrates the role of aeration in shaping yeast population dynamics and modulating a volatile profile in uninoculated wines, and highlights the need for careful air addition to avoid a negative sensory impact on wine flavor and aroma.
\end{abstract}

Keywords: uninoculated fermentation; wild fermentation; oxygen; yeast; wine

\section{Introduction}

Modern commercial winemaking is predominantly performed using pure starter cultures of wine yeast. Inoculation with starter cultures artificially establishes a dominant yeast population at the onset fermentation and enables the production of predictable and reliable wines with largely known quality criteria. Alternatively, grape must will progress through the fermentation process without inoculation, a production practice known as uninoculated, wild or spontaneous fermentation. Here, fermentation relies on the combined activity of a complex microbiota that include those indigenous to the vineyard that are co-harvested with the grapes and those that are resident in the winery. Although the highly variable microbial composition of uninoculated fermentation is accompanied by a higher risk of incomplete fermentation and spoilage, wines fermented this way are associated with distinct and diverse sensory attributes, such as improved mouthfeel and texture and more complex flavor profiles compared to wines inoculated with Saccharomyces cerevisiae [1-4]. 
In the early stages of an uninoculated fermentation, yeasts and yeast-like fungi of the genera Aureobasidium, Rhodotorula, Pichia, Candida, Hanseniaspora and Metschnikowia represent the majority of the microbiota present in grape must [5]. Most of these yeasts decline early after the commencement of fermentation, primarily in response to declining oxygen levels and increasing ethanol concentrations [6-8]. Mildly fermentative yeasts, such as Hanseniaspora spp., Starmerella bacillaris, Torulaspora delbrueckii, Metschnikowia pulcherrima and Lachancea thermotolerans, are able to survive well into the early stages of fermentation but generally decrease in numbers as ethanol concentration increases further, and ultimately, the microbial composition of the ferment converges toward the major wine yeast $S$. cerevisiae [9-12].

Several factors can affect population dynamics during wine fermentation, including vineyard geography, environment and management practices, harvest timing, juice/must processing, fermentation conditions and microbial interactions [13-17]. These factors will alter yeast growth and/or metabolism and can influence whether a particular species or strain contributes to wine aroma and flavor. The addition of the antimicrobial compound sulfur dioxide $\left(\mathrm{SO}_{2}\right)$ prior to the initiation of fermentation is a widely used practice in modern winemaking. $\mathrm{SO}_{2}$ addition has been shown to impact the growth of yeast species during wine fermentation [16,18-20]. Recently, the addition of $\mathrm{SO}_{2}$ was shown to select against many non-Saccharomyces species, while increasing selection for the species Hanseniaspora osmophila in uninoculated Chardonnay ferments [21]. This positive selection was observed at certain $\mathrm{SO}_{2}$ concentrations and it was associated with significant changes in the volatile composition of the resulting wines.

Similarly, aeration during fermentation is a common winemaking practice. In white wines, air addition during fermentation has a positive effect on yeast growth, viability and fermentation efficiency [22-25]. The timing of aeration can also affect fermentation performance, with the addition of air being most beneficial when applied towards the end of the yeast exponential growth phase [26,27]. In addition, aeration can affect the formation of volatile yeast metabolites [25,28-30], and in red wines, can modify tannin composition [31] and reduce or eliminate the concentration of volatile sulfur compounds [32]. However, most of these observations have been made in ferments inoculated with $S$. cerevisiae. Given this limitation, it is unclear if these results can be extrapolated to the management of the complex ecology of uninoculated fermentations.

In this work, the effect of aeration on yeast populations during uninoculated Chardonnay wine fermentation was explored in two successive vintages. In the first vintage (2019), the effect of aeration timing relative to the day of grape crushing was assessed, while in the second vintage (2020), the effect of aeration intensity (different air flow rates) applied at the same time relative to grape crushing was evaluated. Meta-barcoding (phylotyping) analysis was used to assess yeast population dynamics, and the main changes to wine chemical composition were evaluated.

\section{Materials and Methods}

\subsection{Fermentation}

Commercial, high-solids Chardonnay juice (not pre-treated with $\mathrm{SO}_{2}$ during harvesting or processing) was obtained directly after destemming and crushing from Yalumba wineries (Barossa Valley, South Australia) during the 2019 and 2020 vintages. The juice was transferred to sterile 2L Schott bottles, which were sealed with airlocks and incubated at $18^{\circ} \mathrm{C}$. Ferments were continuously stirred at $250 \mathrm{rpm}$ using magnetic stirrers. To assess the impact of aeration on yeast populations, four different aeration treatments were evaluated in each vintage.

In 2019, the timing of aeration was assessed as follows:

I. Control, no aeration provided.

II. Air_24 h, aeration at $6 \mathrm{~mL} / \mathrm{min} 24 \mathrm{~h}$ after crushing, aeration continued for $24 \mathrm{~h}$.

III. Air_ $48 \mathrm{~h}$, aeration at $6 \mathrm{~mL} / \mathrm{min} 48 \mathrm{~h}$ after crushing, aeration continued for $24 \mathrm{~h}$.

IV. Air_ $72 \mathrm{~h}$, aeration at $6 \mathrm{~mL} / \mathrm{min} 72 \mathrm{~h}$ after crushing, aeration continued for $24 \mathrm{~h}$. 
Total oxygen exposure was not statistically different between 2019 aerated ferments (Table S1).

In 2020, the level of aeration was assessed as follows:

I. Control, no aeration provided.

II. Air_low, $24 \mathrm{~h}$ after crushing, aeration at $18 \mathrm{~mL} / \mathrm{min}$ for $48 \mathrm{~h}$.

III. Air_medium, $24 \mathrm{~h}$ after crushing, aeration at $25 \mathrm{~mL} / \mathrm{min}$ for $24 \mathrm{~h}$ and then $35 \mathrm{~mL} / \mathrm{min}$ for another $24 \mathrm{~h}$.

IV. Air_high, $24 \mathrm{~h}$ after crushing, aeration at $50 \mathrm{~mL} / \mathrm{min}$ for $24 \mathrm{~h}$ and then $70 \mathrm{~mL} / \mathrm{min}$ for another $24 \mathrm{~h}$.

Total oxygen exposure for 2020 aerated treatments is indicated in Table S1.

Sterile filtered air $(0.22 \mu \mathrm{m}$, Millipore, Burlington, MA, USA) was sparged into the juice with a $0.2 \mu \mathrm{m}$ stainless-steel diffuser (Mott Corporation, Farmington, CT, USA). The aeration rate for each bottle was controlled using a $0-250 \mathrm{~mL} / \mathrm{min}$ needle valve flow meter connected to a secondary line regulator (Gascon BOC, Melbourne, Australia). The dissolved oxygen concentration in each bottle was monitored with a trace range luminescent robust probe (OXROB25-CL4, PyroScience, Aachen, Germany). All ferments were performed in triplicate. Samples were taken daily for analysis until the end of fermentation $(<2 \mathrm{~g} / \mathrm{L}$ of residual sugars). Although some ferments proceeded faster than others, all ferments were sampled for meta-barcoding at similar sugar concentrations (Table S2). In addition to meta-barcoding, samples were also plated onto Wallerstein Laboratory nutrient agar (Amyl Media Pty Ltd., Dandenong, Australia) and L-lysine medium (Oxoid, Hampshire, UK) to estimate the total and non-Saccharomyces yeast numbers, respectively. The composition of the 2019 juice was: sugar $220 \mathrm{~g} / \mathrm{L}$, yeast assimilable nitrogen (YAN) $412 \mathrm{mg}$ N/L, titratable acidity (TA) $6.0 \mathrm{~g} / \mathrm{L}$ and $\mathrm{pH} 3.41$, whereas the composition of the 2020 juice was: sugar $205 \mathrm{~g} / \mathrm{L}$, YAN $350 \mathrm{mg}$ N/L, TA $7.1 \mathrm{~g} / \mathrm{L}$ and $\mathrm{pH} 3.42$.

\subsection{Analytical Techniques}

Wine density, specific gravity, $\mathrm{pH}$, volatile acidity, alcohol concentration and titratable acidity were determined using a Foss WineScan FT 120 as described by the manufacturer (Foss, Hillerød, Denmark). The concentrations of residual sugar, glycerol, malic, tartaric and citric acids and ethanol were measured by high-performance liquid chromatography (HPLC) using a Bio-Rad HPX-87H column as described previously [33]. Ammonia and free $\alpha$-amino acid nitrogen were determined enzymatically using the Ammonia Enzymatic Test Kit and the Primary Amino Acid Nitrogen Test Kit, respectively (Vintessential Laboratories, Orange, Australia) according to the manufacturer's instructions, and using a GalleryTM Discrete Analyser (Thermo Fisher Scientific, Waltham, MA, USA). Analysis of higher alcohols and acetate and ethyl esters was performed by Metabolomics Australia (Adelaide) using gas chromatography-mass spectrometry (GCMS) with stable isotope dilution analysis (SIDA) as previously described [34]. Low molecular weight sulfur compounds (LMWSC) were determined by using headspace cool-on-column gas chromatography coupled with a sulfur chemiluminescence detector (HS-COC-GC-SCD) [35].

\subsection{Determination of Microbial Populations}

Proportions of each yeast strain were assessed using amplicon-based internal transcribed spacer (ITS) phylotyping as described previously [36,37]. Total DNA was isolated from each sample using the DNeasy PowerFood Microbial kit (Qiagen, Hilden, Germany). Bead-beating was carried out using a combination of $0.1 \mathrm{~mm}$ and $0.5 \mathrm{~mm}$ zirconia/silica beads (BioSpec Products, Oklahoma, OK, USA) in a Precellys Evolution homogenizer (Bertin Instruments, Montigny-le-Bretonneux, France) at 8000 RPM for $4 \times 60 \mathrm{~s}$. Then, $1.0 \mathrm{ng}$ of total DNA from each sample was subjected to a two-step PCR process that amplifies a portion of the fungal ribosomal ITS1 region while adding both custom in-line barcodes and sequences necessary for Illumina sequencing (including compatible Illumina dual-indexes) using the BITS/B58S3 primer set [36]. Sequencing was performed using $2 \times 300 \mathrm{bp}$ chemistry (Ramaciotti Centre for Functional Genomics, Sydney, Australia). Following sequenc- 
ing, paired-end reads were quality trimmed (Trimmomatic v0.38) [38], adaptor trimmed (Cutadapt v1.16) [39] and merged into single synthetic reads (FLASH2 v2.2.00) [40]. Merged reads were de-replicated (USEARCH v10.0.240) [41] and clustered (Swarm v2.2.2) [42] into operational taxonomic units (OTUs) as presented previously [37]. Taxonomic annotation was performed against the UNITE database (qiime_ver8_dynamic_02.02.2019) using a 98\% similarity cut off, assign_taxonomy.py module of QIIME v1.9.1 [43]. Abundances for all fungal OTUs identified in 2019 and 2020 wines are listed in Tables S3 and S4, respectively. Raw reads are available from the BioProject website (accession number PRJNA727920).

\subsection{Data Analysis}

Data analysis and graphical representation for yeast populations were performed using the R packages phyloseq [44], vegan [45], microbiome [46] and ggplot2 [47] in $R$ version 4.0.2 [48]. Samples were filtered for read depth (1000 reads minimum) and OTUs were filtered by abundance $(0.001 \%$ minimum). OTU counts were then standardized to the median sequencing depth and then proportionally normalized by dividing the genus level OTU count by the sum of all OTUs within a sample. Distance-based redundancy analysis (DBRDA) was undertaken using the proportionally normalized data with aeration and fermentation time points as major factors (vegan::dbrda [formula $=\sim$ Treatment ${ }^{*}$ Time_point, dist $=$ bray]). Analysis of variance (ANOVA) was run on the resulting DBRDA analysis using the function aov from the $R$ package stats [48]. Cell concentrations for individual genera and species during fermentation were estimated by dividing the proportional abundance for each genus by the total yeast viable cell count as determined by plating.

Assessment of chemical composition in response to aeration was undertaken using ANOVA and Tukey's multiple comparisons test (alpha $=0.05)$ using the functions aov and HSD.test from the R packages stats [48] and agricolae [49], respectively. Principal component analysis (PCA) was performed to reduce the dimensionality of data and to visualize differences between samples. Data were normalized to unit variance using the PCA function from the R package FactoMineR [50].

Total oxygen exposure was estimated from dissolved oxygen values as follows: data were smoothed using the function frollmean from the package data.table [51] with a rolling window size of 20 . Smoothed data were then baseline corrected using the function baseline.fillPeaks from the package baseline [52]. The total oxygen exposure of each ferment was estimated by calculating the area under the smoothed, baseline-corrected curve using the function pk.calc.auc.all from the package PKNCA [53] and given as $\mathrm{mg} / \mathrm{L} \times \mathrm{h}$.

\section{Results}

The effects of aeration on yeast community structure during fermentation and the chemical composition of Chardonnay wine were assessed in two consecutive vintages. In 2019 , the effect of aeration timing was evaluated by sparging air at a fixed flow rate for $24 \mathrm{~h}$ with aeration treatments starting 24,48 or $72 \mathrm{~h}$ after grapes were crushed. In 2020 , the effect of aeration intensity was evaluated by sparging at three different air flow rates while keeping aeration timing and duration constant (see Materials and Methods for details).

\subsection{Aeration Reduces the Duration of Fermentation}

For the 2019 vintage wines, the timing of aeration had a clear effect on fermentation kinetics (Figure 1A). Fermentation duration decreased upon aeration, with the effect magnified by aeration later in the fermentation process. Whereas when control ferments were completed after 25 days, ferments aerated at $72 \mathrm{~h}$ finished fermentation after only 13 days and those treated at $48 \mathrm{~h}$ and $24 \mathrm{~h}$ finished after 15 and 18 days, respectively. Ferment samples taken at similar sugar concentrations across the different ferments were plated to compare total yeast and non-Saccharomyces yeast populations at four similar stages during fermentation (Table S2). Aeration enabled them to sustain a high total yeast concentration in the later stages of fermentation (Figure $1 \mathrm{C}$ ). Thus, at $80 \%$ sugar consumption, the concentration of yeast in non-aerated ferments decreased to $2 \times 10^{7} \mathrm{cfu} / \mathrm{mL}$, while in aerated 
ferments, yeast concentration remained at $\sim 10^{8} \mathrm{cfu} / \mathrm{L}$. A large part of this differences in microbial abundance could be attributed to higher numbers of non-Saccharomyces yeasts (Figure 1E). Similar yeast counts were obtained regardless of aeration timing, with air addition producing cell counts nearly five times higher than in control ferments.
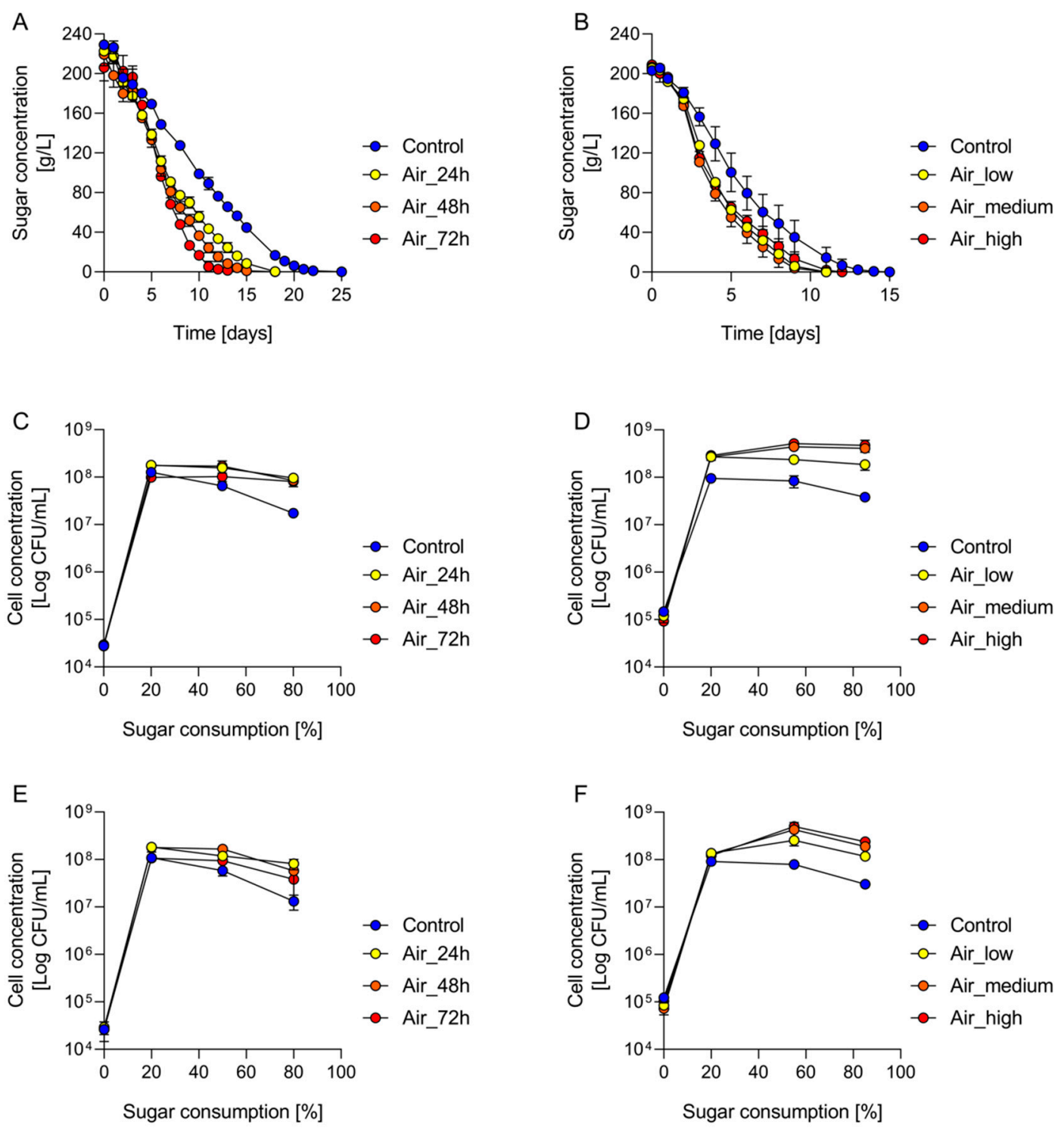

Figure 1. The effect of aeration on fermentation kinetics $(\mathbf{A}, \mathbf{B})$, total viable yeast counts $(\mathbf{C}, \mathbf{D})$ and non-Saccharomyces viable counts (E,F) for the different aeration treatments during 2019 (A,C,E) and 2020 (B,D,F) vintages. All symbols show means of three treatments with error bars showing SD.

For the ferments from the 2020 vintage, aeration was also shown to decrease fermentation duration relative to non-aerated ferments, but there were no further differences in ferment duration associated with modulating aeration intensity (Figure 1B). All aerated ferments finished in 11-12 days, whereas the control ferments required an additional 3-4 days (15 days total fermentation time). Aeration also supported higher total and nonSaccharomyces yeast concentrations later in fermentation, while aeration intensity correlated with total yeast counts (Figure 1D,F). Thus, ferments aerated at low, medium and high intensities reached $2 \times 10^{8} \mathrm{cfu} / \mathrm{mL}, 4 \times 10^{8} \mathrm{cfu} / \mathrm{mL}$ and $5 \times 10^{8} \mathrm{cfu} / \mathrm{mL}$ at $85 \%$ sugar consumption, which was respectively 5-, 10- and 12-times higher than control ferments. 


\subsection{Yeast Populations Are Subtly Shaped by the Timing of Aeration}

In non-aerated ferments, yeast populations transitioned from more complex to less complex compositions over the duration of the ferment. At the beginning of fermentation (T1), four genera accounted for approximately $70 \%$ of the yeast populations. Aureobasidium, Cladosporium, Epicoccum and Hanseniaspora were the prominent genera in 2019, while in 2020, Metschnikowia replaced Hanseniaspora in the list of prominent genera (Figures 2 and 3). By the time $20 \%$ of the sugar had been consumed (T2), $90-95 \%$ of the population comprised just three genera (Hanseniaspora, Saccharomyces and Torulaspora) with Hanseniaspora accounting for more than $75 \%$ and $60 \%$ of the population in 2019 and 2020, respectively. As fermentation continued toward completion, Saccharomyces species progressively increased their dominance in non-aerated ferments such that by the time $85 \%$ of sugar had been consumed (T4), this genus represented 40\% and 50\% of the population in 2019 and 2020, respectively (Figures 2 and 3).
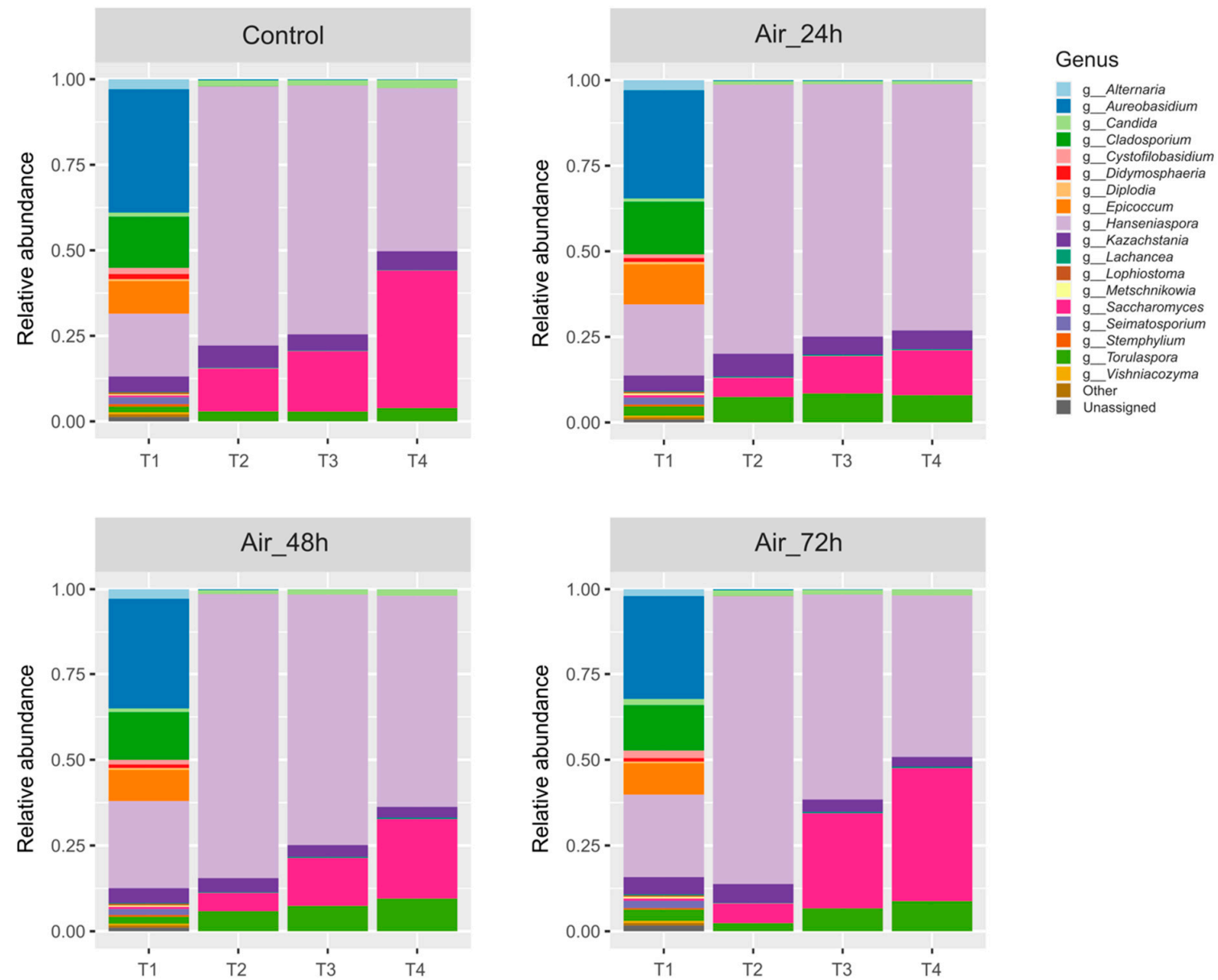

Figure 2. Genus-level metabarcoding analysis of community response to aeration given at $24 \mathrm{~h}, 48 \mathrm{~h}$ and $72 \mathrm{~h}$ post-crushing of grapes in the 2019 vintage. Ferment samples were taken at four time points: T1, 0\%; T2, 20\%; T3, 50\%; T4, 80\% of sugar consumption. All sub-columns show mean percentages of three replicates.

Aeration altered yeast community composition relative to non-aerated ferments in both vintages, particularly in the abundance of specific genera within yeast populations. In the 2019 experiment, the timing of aeration relative to grape crush was evaluated. Aeration within $48 \mathrm{~h}$ of grape crush favored the growth of Hanseniaspora and Torulaspora (Figure 2). To study yeast population changes in more detail, total yeast counts and microbial profiling data were combined to estimate cell concentrations for individual genera and species during fermentation. In 2019, the estimated concentrations of Hanseniaspora, Lachancea, Torulaspora and Kazachstania were higher in aerated treatments compared to the control (Figure 4A). 
At time point T4, the difference in cell concentration was one order of magnitude greater for Hanseniaspora, Lachancea and Torulaspora in aerated ferments. Minor differences were observed for Saccharomyces with estimated cell numbers correlating with the timing of aeration: control and ferments aerated at $24 \mathrm{~h}, 48 \mathrm{~h}$ and $72 \mathrm{~h}$ reached $7 \times 10^{6} \mathrm{cfu} / \mathrm{mL}$, $1 \times 10^{7} \mathrm{cfu} / \mathrm{mL}, 2 \times 10^{7} \mathrm{cfu} / \mathrm{mL}$ and $3 \times 10^{7} \mathrm{cfu} / \mathrm{mL}$, respectively (Figure $4 \mathrm{~A}$ ).
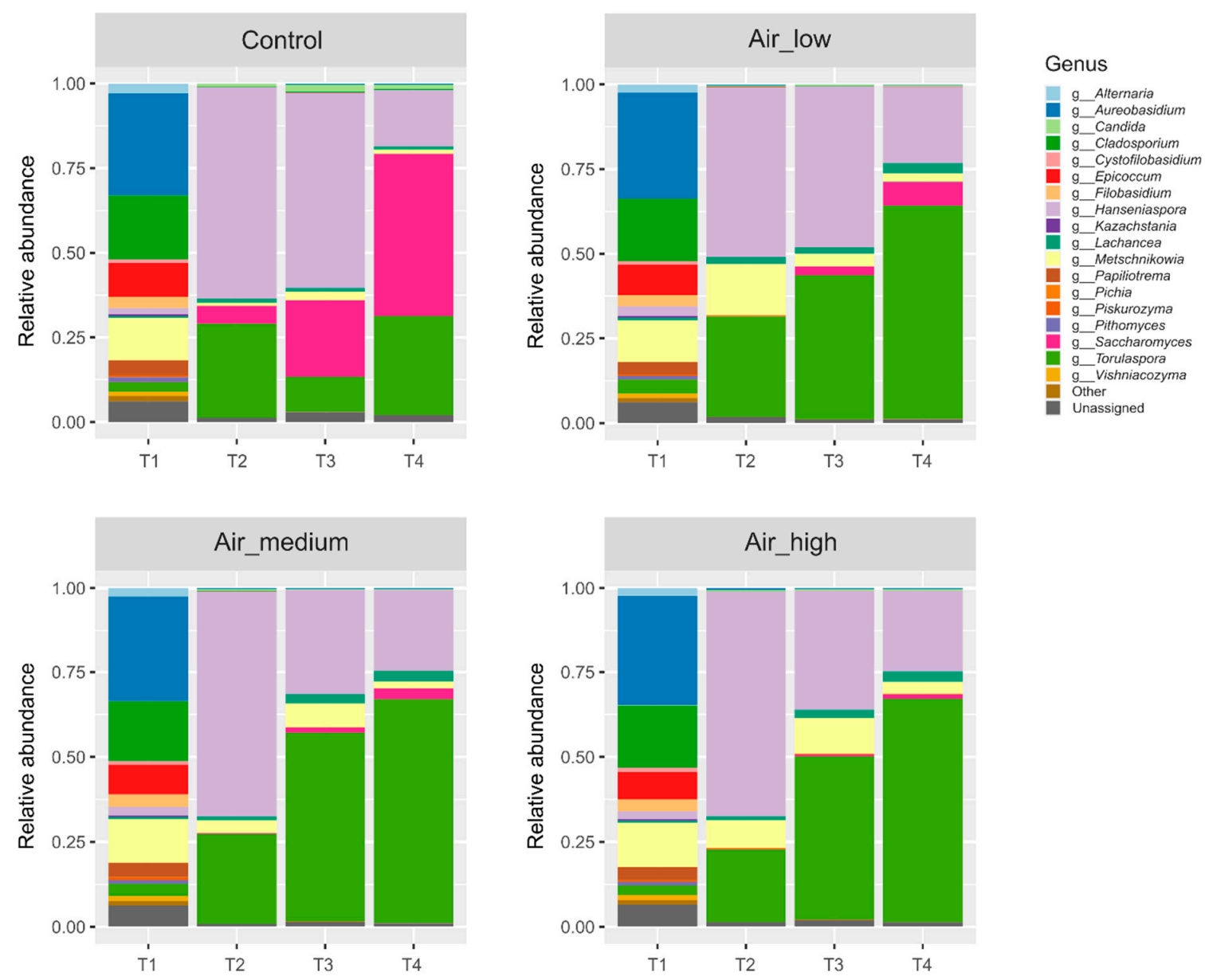

Figure 3. Genus-level metabarcoding analysis of community response to aeration given at $24 \mathrm{~h}$ post-grape crush in the 2020 vintage. Ferment samples were taken at four time points: T1, 0\%; T2, 20\%; T3, 55\%; T4, 85\% of sugar consumption. All sub-columns show mean percentages of three replicates.

Five Hanseniaspora species were detected in the 2019 ferments. H. uvarum was the most abundant member of the genus, reaching an estimated $10^{8} \mathrm{cfu} / \mathrm{mL}$. H. opuntiae and $H$. vineae were estimated at close to $10^{7} \mathrm{cfu} / \mathrm{mL}$, whereas $H$. osmophila and $H$. valbyensis reached approximately $10^{6} \mathrm{cfu} / \mathrm{mL}$ (Figure 4B). In all cases, aeration appeared to allow for the prolonged maintenance of the maximum population size of Hanseniaspora species rather than enhancing them, regardless of when aeration was applied. The one exception was $H$. valbyensis whose estimated cell numbers were less well supported when ferments were aerated at $24 \mathrm{~h}$ rather than at 48 or $72 \mathrm{~h}$ (Figure $4 \mathrm{~B}$ ).

Experiments in 2019 showed that earlier aeration preferentially benefitted non-Sacch aromyces yeasts. Experiments in 2020 were designed to evaluate whether increasing the intensity of aeration at that early time point could be used to further modulate nonSaccharomyces populations. In the 2020 experiments, aeration increased the abundance of Torulaspora and Metschnikowia, with increased abundance of Torulaspora particularly evident later in fermentation (Figure 3). This was reflected in the higher estimated cell numbers of the four main non-Saccharomyces genera, Hanseniaspora, Lachancea, Metschnikowia and Torulaspora, which were higher in aerated ferments than in non-aerated controls, particularly 
toward the end of fermentation (Figure 5A). In contrast, Saccharomyces cell numbers in non-aerated ferments were estimated to be higher later in fermentation than in other treatments. Aeration intensity had a minor effect on the cell concentrations of the main nonSaccharomyces genera, with the ferments that received the lowest aeration intensity having lower estimated cell numbers than the ferments that received medium or high-intensity aeration (Figure 5A).

A
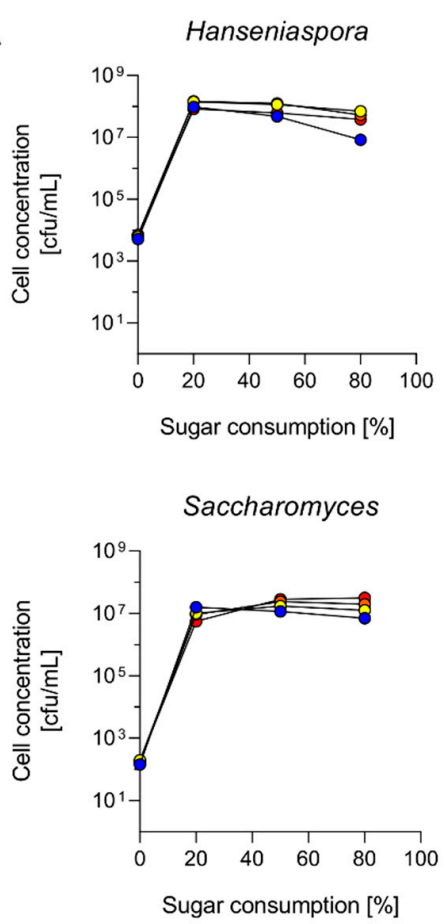

B

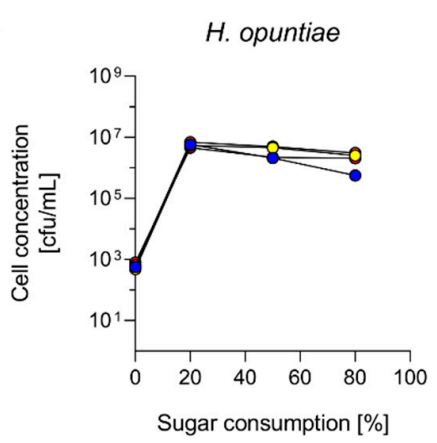

H. uvarum

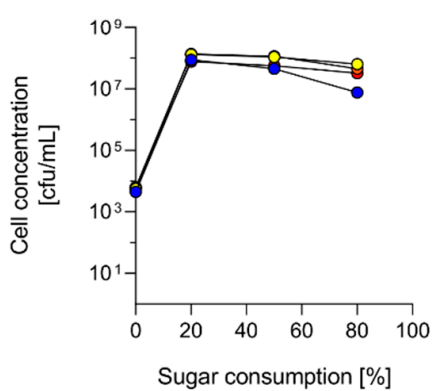

Lachancea

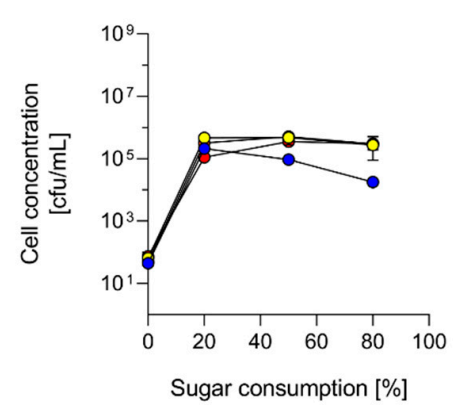

Torulaspora

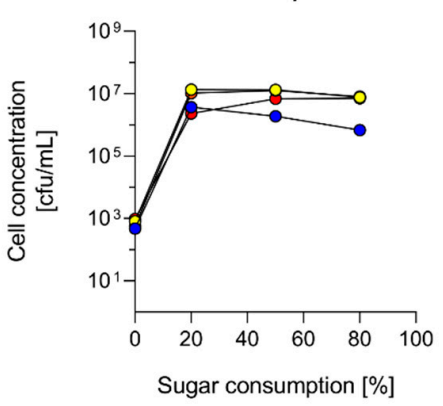

H. osmophila

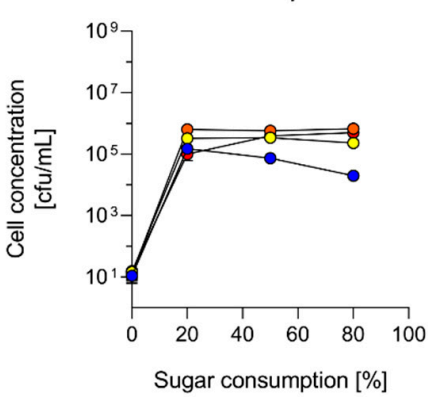

$H$. vineae

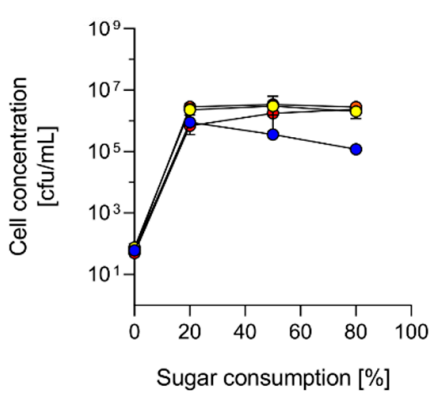

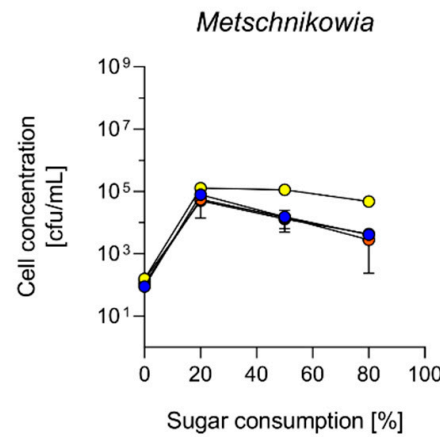
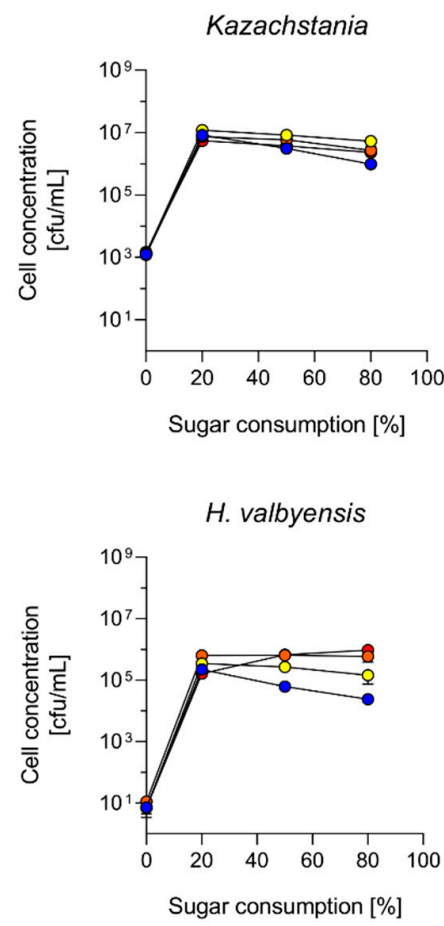

- Control

-o- Air_24h

-o- Air_48h

- Air_72h

Figure 4. Estimated yeast counts for the main genera (A) and for Hanseniaspora species (B) found in ferments from the 2019 vintage. All symbols show means of three treatments with error bars showing SD. 
A
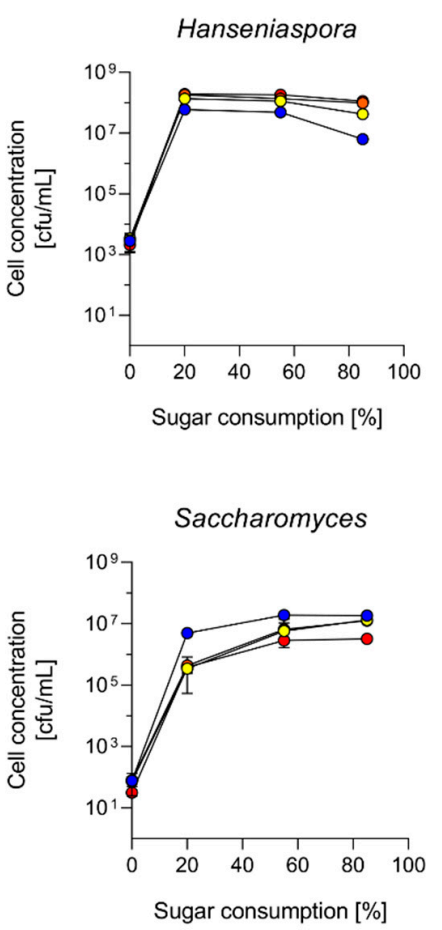

B

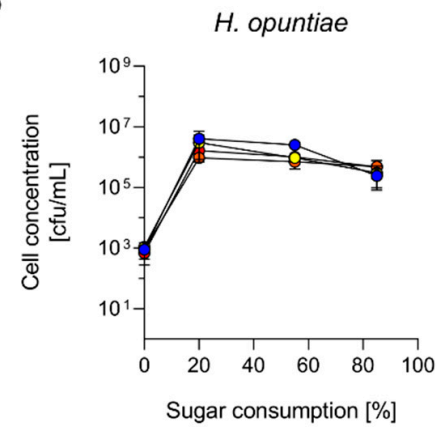

H. uvarum

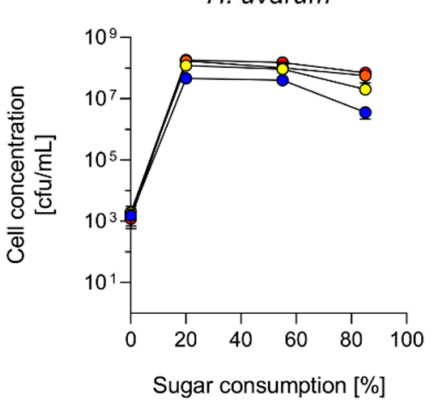

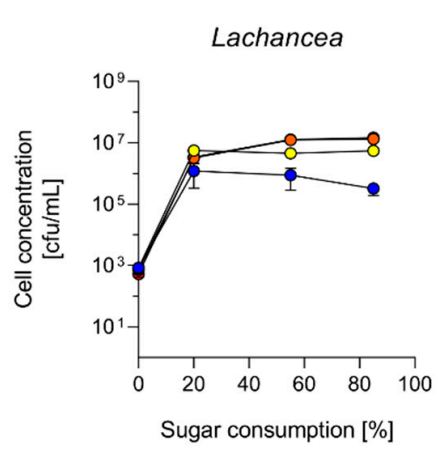
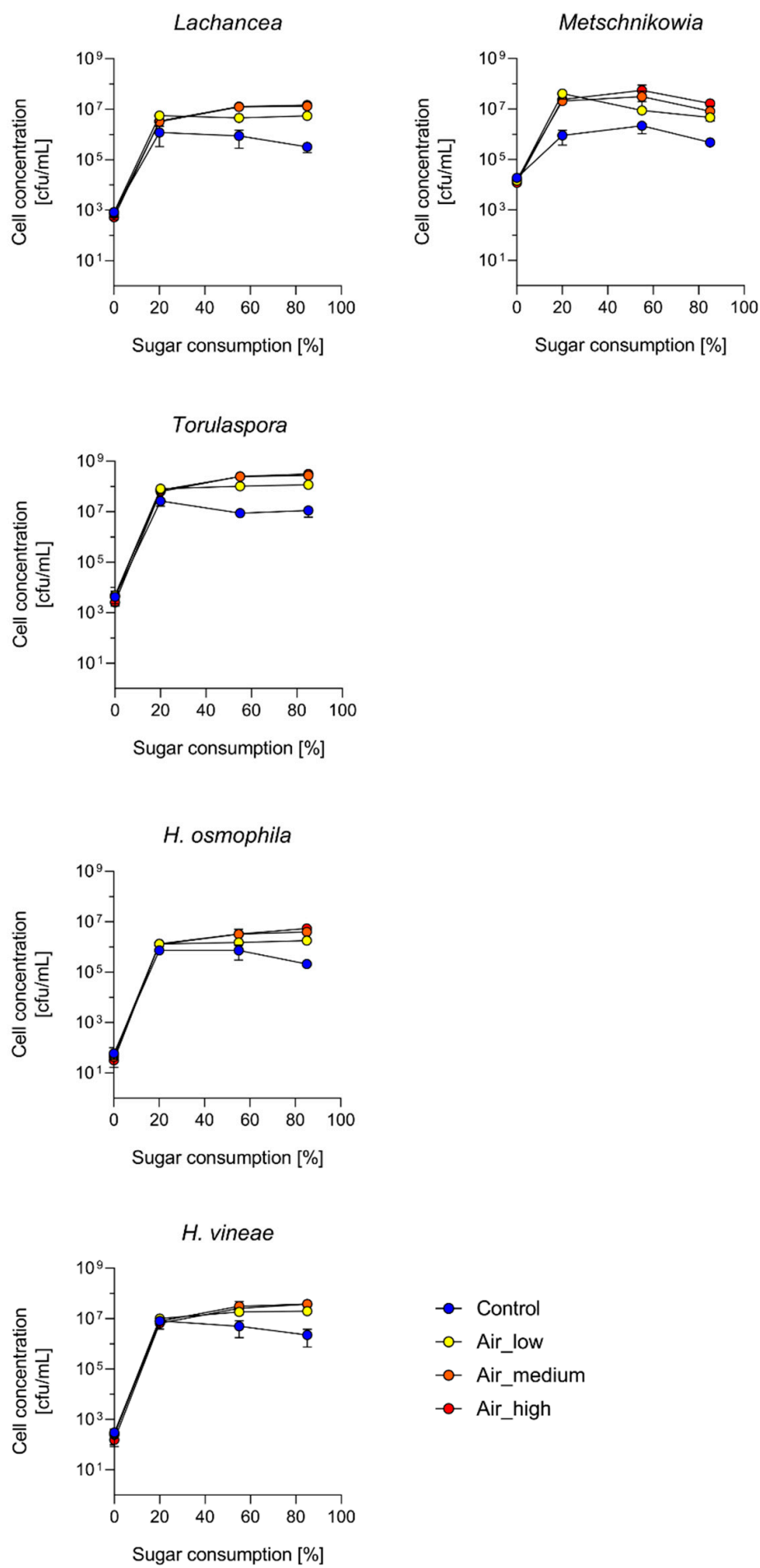

Figure 5. Estimated yeast counts for the main yeast genera (A) and for Hanseniaspora species (B) found in ferments from the 2020 vintage. All symbols show means of three treatments with error bars showing SD.

Four Hanseniaspora species were observed in 2020 ferments with $H$. uvarum being the most abundant (Figure 5B). H. opuntiae cell concentration was similar for all treatments throughout fermentation, although lower numbers were observed in aerated ferments compared to the control at T3 (55\% sugar consumption). In contrast, the estimated cell concentrations of H. osmophila, H. uvarum and H. vineae were higher, up to 25-, 20- and 15-times, respectively, in aerated ferments than in the non-aerated control, particularly in the last two time points. These three species responded to aeration intensity; their numbers 
increased in ferments aerated at medium and high intensities compared to cultures with low aeration intensity. H. osmophila, H. uvarum and H. vineae increased 3-, 3.5- and 2-times, respectively (Figure $5 \mathrm{~B}$ ).

Distance-based redundancy analysis (DBRDA) was used to assess the relative contributions of aeration and/or fermentation stage to the changes in microbial structure observed in both vintages. The results showed that, for the 2019 and 2020 vintages, both aeration and fermentation stage affected community structure, and that an interaction between both factors also played a role (Table S5). The primary factor driving community composition was fermentation stage, which explained $84 \%$ and $70 \%$ of the variation observed in 2019 and 2020, respectively, whereas aeration treatment explained 13\% and 17\% in 2019 and 2020, respectively. This was visualized in the principal coordinates analysis (PCoA) plot for 2019 wines, which showed a clear separation according to fermentation stage, primarily $\mathrm{T} 1$ on the first axis, and T2, T3 and T4 on the second axes. In addition, samples from T4 were distributed into three groups on the second axis (Figure S1A). One group consisted of control ferments and cultures aerated at $72 \mathrm{~h}$, a second group comprised ferments aerated at $48 \mathrm{~h}$ and the final group included ferments aerated at $24 \mathrm{~h}$. Similarly for 2020 wines, PCoA revealed a clear separation according to fermentation stage and a separation between control and aerated ferments at T3, which was not so well defined at T4 (Figure S1B).

\subsection{Chemical Composition and Volatile Profile}

Aeration altered the chemical composition of wines from both vintages. For 2019 wines, glycerol concentration was higher in ferments aerated at $24 \mathrm{~h}$ and $48 \mathrm{~h}$ than in other treatments (increase of 1.8-2.0 g/L), while similar ethanol and residual sugar concentrations were found among treatments (Table 1). The total concentration of esters excluding ethyl acetate was lower in ferments provided with aeration at $24 \mathrm{~h}$ and $48 \mathrm{~h}$ (decrease of $0.8-0.9 \mathrm{mg} / \mathrm{L})$. This difference was mainly due to lower concentrations of acetate esters, including 2-methylpropyl acetate and 2- and 3-methylbutyl acetate (Table S6). Interestingly, the concentrations of ethyl hexanoate, ethyl octanoate and ethyl decanoate correlated with the timing of aeration, with the lowest concentration found in ferments aerated at $24 \mathrm{~h}$ (decreased by $0.13,0.21$ and $0.14 \mathrm{mg} / \mathrm{L}$ respectively) relative to non-aerated control ferments, which showed the highest concentrations.

The concentrations of volatile acids were lower in aerated ferments than in control wines, reduced by 2.2, 1.7 and $0.7 \mathrm{mg} / \mathrm{L}$ in Air_24, Air_28 and Air_72, respectively, due mainly to decreased concentrations of medium-chain fatty acids (MCFAs) including hexanoic, octanoic and decanoic acids. The acetic acid concentration was highest in ferments aerated at $24 \mathrm{~h}(464 \mathrm{mg} / \mathrm{L})$ and lowest in ferments provided with aeration at $72 \mathrm{~h}$ $(227 \mathrm{mg} / \mathrm{L})$. Conversely, ethyl acetate concentration, the other main contributor to volatile acidity alongside acetic acid, was significantly higher in ferments aerated at $72 \mathrm{~h}$, increasing by $100-129 \mathrm{mg} / \mathrm{L}$ compared to other treatments. Succinic acid concentration increased from $0.6 \mathrm{~g} / \mathrm{L}$ in non-aerated ferments to $1.3 \mathrm{~g} / \mathrm{L}$ in wines aerated at $72 \mathrm{~h}$ (Table 1). Malic acid concentrations were substantially lower in non-aerated ferments, although this is difficult to reconcile with the experimental design and was not replicated in 2020 .

The change in chemical composition resulting from variations in aeration intensity was distinct from that observed in response to variations in aeration timing. Ethanol concentrations were reduced by between $0.3-0.5 \% v / v$ in ferments that received medium and high aeration intensities relative to non-aerated ferments (Table 2). Similar glycerol concentrations were found among treatments. The total concentration of esters excluding ethyl acetate was reduced by half in ferments receiving low and medium aeration intensity treatments relative to control wines and ferments receiving high-intensity aeration, mainly due to lower concentrations of ethyl hexanoate, ethyl octanoate and ethyl decanoate (Table S7). The total acetate ester concentration was lower in wines from aerated ferments than in control wines (decrease of 2.55, 2.22 and $1.21 \mathrm{mg} / \mathrm{L}$ ). This was associated with large decreases in the concentrations of 3-methylbutyl acetate and hexyl acetate. Aerated 
ferments showed increased total higher alcohol concentrations (increase of $95 \mathrm{mg} / \mathrm{L}$ ) driven predominantly by 2-methyl propanol and 2-phenyl ethanol.

Table 1. Post-fermentation chemical composition for vintage 2019 wines.

\begin{tabular}{|c|c|c|c|c|c|c|}
\hline \multicolumn{7}{|c|}{ Vintage 2019} \\
\hline Compound & Control & Air_24 & Air_48 & Air_72 & F Value & $p$ Value \\
\hline Alcohol $[\% v / v]$ & $14.4 \pm 0.1$ & $14.7 \pm 0.2$ & $14.9 \pm 0.3$ & $14.2 \pm 0.4$ & 4.4 & 0.048 \\
\hline Residual sugar [g/L] & $0.0 \pm 0.0$ & $0.4 \pm 0.3$ & $0.0 \pm 0.0$ & $0.0 \pm 0.0$ & 2.8 & 0.120 \\
\hline Glycerol [g/L] & $7.9 \pm 0^{b}$ & $9.9 \pm 0.2^{\mathrm{a}}$ & $9.6 \pm 0.8^{a}$ & $8.7 \pm 0.4^{\mathrm{a}, \mathrm{b}}$ & 10.6 & 0.005 \\
\hline Malic acid [g/L] & $0.4 \pm 0^{\mathrm{c}}$ & $2.6 \pm 0.1^{\mathrm{a}}$ & $2.6 \pm 0.1^{\mathrm{a}}$ & $2.2 \pm 0.1^{b}$ & 419.8 & 0.000 \\
\hline Succinic acid [g/L] & $0.6 \pm 0.1^{c}$ & $0.8 \pm 0^{\mathrm{b}}$ & $0.7 \pm 0.1^{b, c}$ & $1.3 \pm 0.1^{\mathrm{a}}$ & 37.6 & 0.000 \\
\hline Acetic acid [mg/L] & $335 \pm 15^{b}$ & $464 \pm 49^{a}$ & $413 \pm 39^{a, b}$ & $227 \pm 9^{c}$ & 21.2 & 0.001 \\
\hline Ethyl acetate [mg/L] & $124 \pm 7^{b}$ & $136 \pm 7^{b}$ & $160 \pm 23^{b}$ & $252 \pm 13^{a}$ & 37.9 & 0.000 \\
\hline Total esters $[\mathrm{mg} / \mathrm{L}]^{1}$ & $1.9 \pm 0.0^{\mathrm{a}}$ & $0.9 \pm 0.0^{b}$ & $1.1 \pm 0.1^{b}$ & $1.8 \pm 0.1^{\mathrm{a}}$ & 94.0 & 0.000 \\
\hline Total higher alcohols [mg/L] & $199 \pm 15$ & $209 \pm 3$ & $199 \pm 23$ & $231 \pm 10$ & 2.2 & 0.173 \\
\hline Total volatile acids $[\mathrm{mg} / \mathrm{L}]^{2}$ & $8.5 \pm 0.1^{a}$ & $6.3 \pm 0.2^{c}$ & $6.8 \pm 0.1^{\mathrm{c}}$ & $7.8 \pm 0.4^{b}$ & 59.2 & 0.000 \\
\hline Total LMWSC $[\mu \mathrm{g} / \mathrm{L}]$ & $32 \pm 1$ & $19 \pm 5$ & $22 \pm 6$ & $29 \pm 9$ & 3.8 & 0.066 \\
\hline
\end{tabular}

${ }^{1}$ Excluding ethyl acetate. ${ }^{2}$ Excluding acetic acid. LMWSC, low molecular weight sulfur compounds. Data are mean of three replicates with SD. Treatment means in rows without a common letter differ according to the post-hoc Tukey simultaneous test for difference of means for a one-way ANOVA (alpha $=0.05$ ).

Table 2. Post-fermentation chemical composition for vintage 2020 wines.

\begin{tabular}{|c|c|c|c|c|c|c|}
\hline \multicolumn{7}{|c|}{ Vintage 2020} \\
\hline Compound & Control & Air_Low & Air_Medium & Air_High & F Value & $p$ Value \\
\hline Alcohol $[\% v / v]$ & $12.7 \pm 0.1^{a}$ & $12.8 \pm 0.1^{a}$ & $12.4 \pm 0.1^{b}$ & $12.2 \pm 0.1^{c}$ & 25.2 & 0.000 \\
\hline Residual sugar [g/L] & $0.0 \pm 0.0$ & $0.0 \pm 0.0$ & $0.0 \pm 0.0$ & $0.0 \pm 0.0$ & 0.0 & 1.000 \\
\hline Glycerol [g/L] & $7.9 \pm 0.3$ & $9 \pm 0.2$ & $8.3 \pm 0.5$ & $8.5 \pm 0.4$ & 3.4 & 0.073 \\
\hline Malic acid [g/L] & $2.3 \pm 0.2^{\mathrm{a}}$ & $2.2 \pm 0.4^{\mathrm{a}}$ & $1.3 \pm 0.2^{b}$ & $1.3 \pm 0.1^{b}$ & 16.7 & 0.001 \\
\hline Succinic acid $[\mathrm{g} / \mathrm{L}]$ & $0.5 \pm 0^{\mathrm{b}}$ & $0.8 \pm 0^{\mathrm{a}}$ & $0.8 \pm 0.1^{\mathrm{a}}$ & $0.8 \pm 0.1^{\mathrm{a}}$ & 46.5 & 0.000 \\
\hline Acetic acid [mg/L] & $293 \pm 48^{b}$ & $255 \pm 46^{b}$ & $589 \pm 46^{\mathrm{a}}$ & $685 \pm 82^{a}$ & 41.4 & 0.000 \\
\hline Ethyl acetate $[\mathrm{mg} / \mathrm{L}]$ & $229 \pm 27^{c}$ & $195 \pm 26^{c}$ & $573 \pm 146^{b}$ & $879 \pm 128^{a}$ & 32.0 & 0.000 \\
\hline Total esters $[\mathrm{mg} / \mathrm{L}]^{1}$ & $6.8 \pm 0.6^{\mathrm{a}}$ & $3.4 \pm 0.3^{b}$ & $4.5 \pm 0.1^{b}$ & $5.7 \pm 0.5^{\mathrm{a}}$ & 36.6 & 0.000 \\
\hline Total higher alcohols [mg/L] & $93 \pm 3^{b}$ & $193 \pm 10^{a}$ & $181 \pm 6^{\mathrm{a}}$ & $190 \pm 2^{a}$ & 179.5 & 0.000 \\
\hline Total volatile acids $[\mathrm{mg} / \mathrm{L}]^{2}$ & $75 \pm 2$ & $76 \pm 4$ & $98 \pm 27$ & $104 \pm 4$ & 3.5 & 0.070 \\
\hline Total LMWSC $[\mu \mathrm{g} / \mathrm{L}]$ & $6.2 \pm 1.2^{b}$ & $7.4 \pm 0.5^{\mathrm{a}, \mathrm{b}}$ & $8.5 \pm 0.9^{a}$ & $7.1 \pm 0.2^{\mathrm{a}, \mathrm{b}}$ & 4.2 & 0.046 \\
\hline
\end{tabular}

${ }^{1}$ Excluding ethyl acetate. ${ }^{2}$ Excluding acetic acid. LMWSC, low molecular weight sulfur compounds. Data are mean of three replicates with SD. Treatment means in rows without a common letter differ according to the post-hoc Tukey simultaneous test for difference of means for a one-way ANOVA (alpha $=0.05$ ).

Although the total concentration of volatile acids was similar among treatments, the balance in the types of acids present changed in response to aeration; control wines had higher concentrations of octanoic and decanoic acids (not detected in aerated ferments), whereas the concentrations of 2-methyl propanoic (increased by 4.5, 5.3 and $4.9 \mathrm{mg} / \mathrm{L}$ ) and 2-methyl butanoic acids (increased by $0.5 \mathrm{mg} / \mathrm{L}$ ) increased in aerated ferments. Acetic acid and ethyl acetate concentrations were also increased with increasing aeration intensity, reaching 685 and $879 \mathrm{mg} / \mathrm{L}$, respectively, in wines provided with a high aeration intensity (Table 2). Succinic acid concentration was moderately higher in aerated ferments, increasing by $0.3 \mathrm{mg} / \mathrm{L}$, relative to control wines. Interestingly, the malic acid concentration was lower in ferments aerated with medium and high oxygen exposure, reducing by an average of $1 \mathrm{~g} / \mathrm{L}$.

The overall effect of aeration on chemical composition in both vintages was visualized in the scores and loading plots resulting from principal component analysis (Figure 6). In 2019, ferments aerated after $24 \mathrm{~h}$ or $48 \mathrm{~h}$ clustered close to each other, located to the left of the plot (Figure 6A) with high concentrations of compounds negatively loaded on PC1, specifically with 2-phenyl ethanol, 3-methyl butanoic acid, glycerol, hexanol and 
propanoic acid contributing to the separation (Figure 6A,B). Ferments aerated after $72 \mathrm{~h}$ were more closely related with the control wines, being more centrally positioned, and associated with higher concentrations of compounds positively loaded on PC2, namely 2-phenylethyl acetate, ethyl acetate and dimethyl sulfide. Control wines were positioned to the far right of the plot and were associated with compounds positively loaded on PC1, specifically 2-methyl butanol, 2-methylpropyl acetate, butanoic acid, carbon disulfide and ethyl butanoate.

A
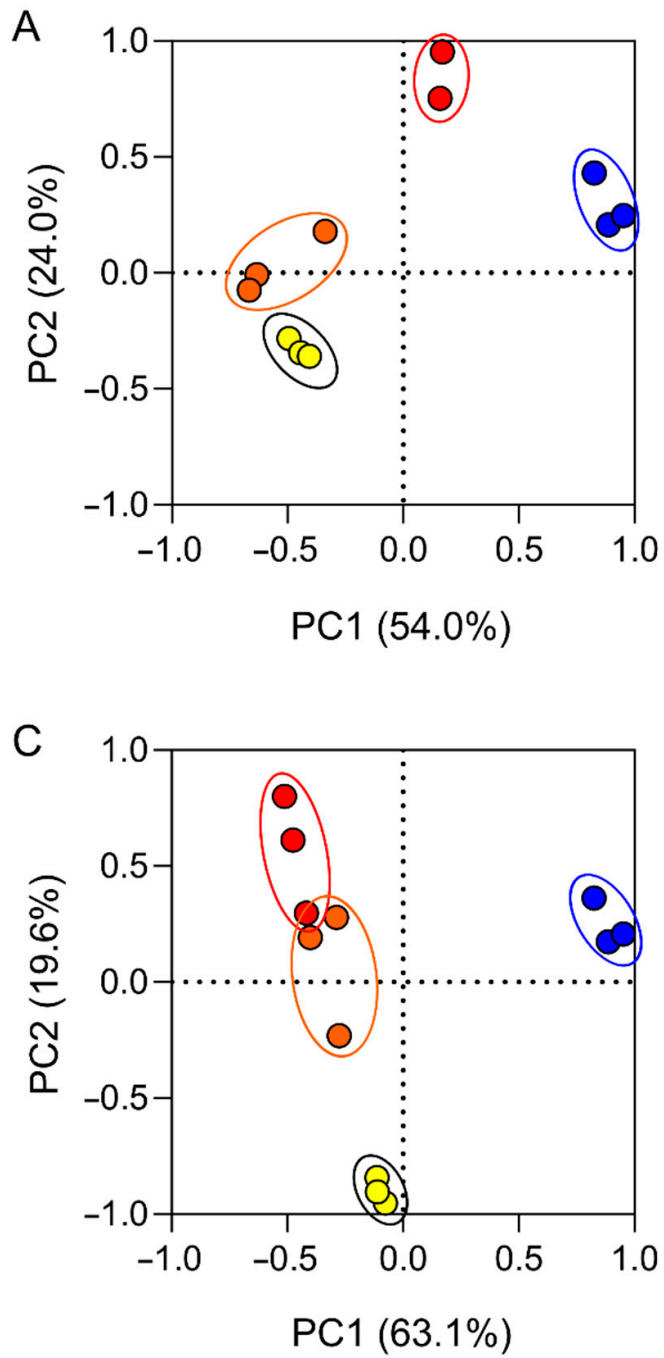
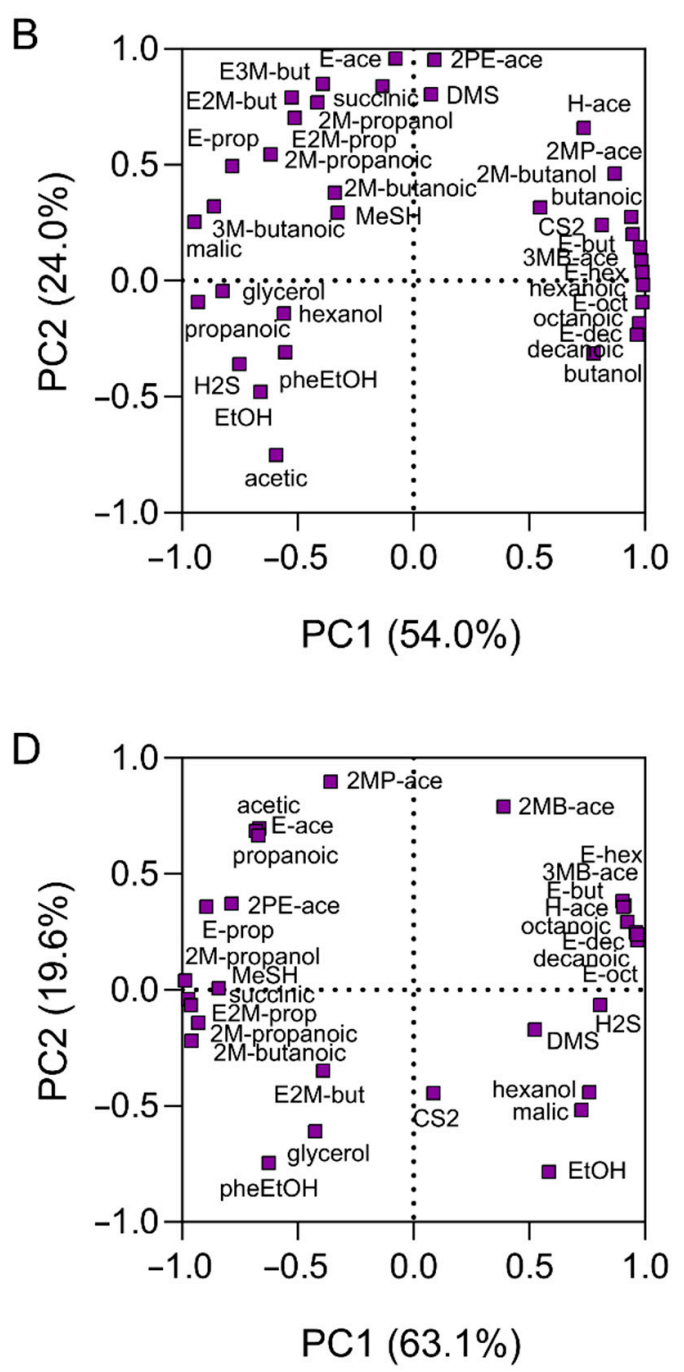

Figure 6. Principal component analysis for ferments from the 2019 and 2020 vintages. (A) scores for 2019 wines, (B) loadings for 2019 wines, (C) scores for 2020 wines, (D) loadings for 2020 wines. Individual winemaking replicates are shown, with ellipses drawn to visually indicate the difference between replicates. 2M-butanoic, 2-methyl butanoic acid; 3M-butanoic, 3-methyl butanoic acid; 2M-butanol, 2-methyl butanol; 2MB-ace, 2-methylbutyl acetate; 2M-propanoic, 2-methyl propanoic acid; 2M-propanol, 2-methyl propanol; 2MP-ace, 2-methylpropyl acetate; 2PE-ace, 2-phenylethyl acetate; 3MB-ace, 3-methylbutyl acetate; 3M-butanol, 3-methyl butanol; acetic, acetic acid; butanoic, butanoic acid; butanol, butanol; CS2, carbon disulfide; decanoic, decanoic acid; DMS, dimethyl sulfide; EtOH, ethanol; E2M-but, ethyl-2-methyl butanoate; E3M-but, ethyl-3-methyl butanoate; E2M-prop, ethyl-2-methyl propanoate; E-ace, ethyl acetate; E-but, ethyl butanoate; E-dec, ethyl decanoate; E-hex, ethyl hexanoate; E-prop, ethyl propanoate; E-oct, ethyl octanoate; glycerol, glycerol; H2S, hydrogen sulfide; hexanoic, hexanoic acid; hexanol, hexanol; H-ace, hexyl acetate; malic, malic acid; MeSH, methanethiol; octanoic, octanoic acid; pheEtOH, 2-phenyl ethanol; propanoic, propanoic acid; succinic, succinic acid.

In 2020, the first principal component described $63 \%$ of the variation in wine chemical composition, with the main driver for sample separation along this axis being whether 
ferments were aerated. Ferments sparged at medium and high intensities clustered next to each other and separated along PC2 from the ferments aerated at a low intensity (Figure 6C). Whereas separation of highly aerated ferments was associated with higher acetic acid, ethyl acetate and propanoic acid concentrations, 2-phenyl ethanol and glycerol contributed to the separation of low intensity aerations (Figure 6C,D). Control wines clustered separately to other treatments and were associated with compounds positively loaded on PC1, specifically the MCFAs and their ethyl esters.

\section{Discussion}

Currently, the quest for novel and distinct wine flavor profiles has led winemakers to increase the use of uninoculated wine fermentations in commercial settings. While several winemaking factors can affect the composition and structure of native microbial populations [13], detailed information on how to modulate these factors to systematically influence population structure and shape wine style are only beginning to be investigated $[18,21]$. Particularly interesting is the use of $\mathrm{SO}_{2}$ to positively select for $\mathrm{H}$. osmophila in uninoculated ferments and consequently change the wine volatile profile [21].

Oxygen management, which includes oxygen exclusion or air addition, is an important tool in winemaking, where it can be used to modify wine aroma, flavor and mouthfeel, and influence wine style $[54,55]$. Air addition has been shown to increase yeast viability and improve fermentation efficiency [22-25], at least in white wine production. This was observed in the present study across all aerated ferments in both vintages. While the timing of aeration had a considerable effect on fermentation duration, different aeration intensities only differed when compared to the non-aerated control ferments. Improvement of fermentation performance has been associated with oxygen increasing the concentration of unsaturated fatty acids (UFAs) and limiting the synthesis of MCFAs [56]. Thus, under anaerobic conditions, the deficiency in UFAs and the increase of saturated fatty acids (SFAs) results in a low unsaturation index (UFAs/SFAs). This index determines cell membrane fluidity and the ability to resist ethanol toxicity [57]. Given the considerable increase in viable population size for non-Saccharomyces yeasts in the aerated ferments, it is possible that these species respond differently to air addition relative to $S$. cerevisiae. In fact, in response to aeration, $H$. vineae has been shown to boost the content of UFAs in its cell membranes by primarily increasing palmitoleic acid, in contrast to $S$. cerevisiae, which simultaneously increased palmitoleic acid and oleic acid content [57]. More studies are needed to confirm if this also applies to other non-Saccharomyces species.

Oxygen availability or aeration has been shown to increase the survival and improve the persistence of several non-Saccharomyces yeasts, including T. delbrueckii, L. thermotolerans, Starmerella bacillaris, M. pulcherrima and H. vineae, when these species have been co-inoculated with S. cerevisiae [57-60]. Here, we observed that this was also the case in uninoculated fermentations, with the total population of non-Saccharomyces yeasts showing increased viability in both vintages, and species from the genera Hanseniaspora, Lachancea, Metschnikowia and Torulaspora increasing their representation within the population. Although oxygen availability influences population dynamics, clear species-dependent differences have been reported [60]. In the 2019 experiment reported here, a particularly large increase in the relative abundance of Hanseniaspora species was found in aerated ferments, whereas in the 2020 experiment, $T$. delbrueckii was clearly more abundant than other species in aerated ferments. Additionally, we found that within the Hanseniaspora genus, different species varied subtly in their response to aeration. While H. opuntiae and $H$. uvarum populations decreased at the end of fermentation regardless of aeration, $H$. osmophila, $H$. vineae and $H$. valbyensis sustained their numbers until the end of fermentation. The reason(s) for this differential behavior requires further exploration.

Interactions between yeast species that include a multitude of positive and negative yeast-yeast interactions can also alter population structure [61]. During wine fermentation, the presence of S. cerevisiae favors the persistence of some non-Saccharomyces yeast species, while it suppresses the growth and contribution of others [61,62]. At the same time, 
non-Saccharomyces strains can negatively affect the growth of $S$. cerevisiae and result in incomplete or stuck fermentations [63,64]. Although yeast-yeast interactions have not been studied in aerated ferments, they could potentially explain the different viability and persistence profiles observed in some non-Saccharomyces species.

Wine flavor and aroma depend on the concentration of hundreds of metabolites formed during fermentation, which in turn, are affected by the presence and metabolism of different yeast species in the ferment [1]. In both vintages, aeration resulted in wines with altered chemical compositions. This has been observed in aerated ferments co-inoculated with non-Saccharomyces and S. cerevisiae strains $[57,60,65]$. In fact, major fermentation products and volatile compounds, including ethanol, glycerol, lactic acid, ethyl and acetate esters, MCFAs and higher alcohols, have been demonstrated to be significantly affected by air supplementation $[57,60]$. For the 2019 wines, early aeration ( $24 \mathrm{~h}$ and $48 \mathrm{~h}$ ) resulted in wines with similar volatile profiles, while late aeration generated wines more similar to the non-aerated control. In general, aeration resulted in a decrease in the concentration of MCFAs and their associated esters, an observation consistent with the work undertaken using single inoculum systems $[30,66,67]$. Although a link between community structure and volatile profile is possible, aeration can also affect yeast metabolism, altering the volatile profile without necessarily affecting the population structure. Indeed, the impact of aeration on yeast physiology extends beyond the aeration phase, influencing fermentation activity and the formation of volatile compounds after air addition has ceased [57].

Aeration intensity had a strong effect on the formation of ethyl acetate and acetic acid, with concentrations reaching values considered detrimental for wine quality in wines provided with medium and high aeration intensities. The relationship between aeration and ethyl acetate production in S. cerevisiae has previously been shown [68]. Similarly, wines produced with the non-Saccharomyces yeasts T. delbrueckii or M. pulcherrima and provided with high aeration intensity showed aroma and sensory profiles that negatively affected wine quality [69]. The resulting wines, however, showed reduced ethanol concentration. These findings indicate that while air addition is a tool that can be employed to manage microbial populations and wine style, excessive aeration can be damaging for wine flavor and aroma, with white ferments likely to be more sensitive to the use of aeration than red ferments.

In summary, we have shown that aeration of non-inoculated ferments can be used to stimulate fermentation activity and reduce the duration of fermentation. Timing of aeration was critical in affecting a maximum reduction in fermentation time, which was achieved with aeration later in the ferment. It is likely that the later aeration benefited the resident $S$. cerevisiae population to a greater degree that the non-Saccharomyces population. While earlier aerations still reduced overall fermentation time, the effect was diminished. Earlier aeration, however, did maximize the reshaping of yeast populations, affecting the growth, viability and likely metabolism of non-Saccharomyces yeast species. Overall, wines provided with aeration had a different chemical composition than non-aerated wines, with the magnitude of the change in the concentration of some compounds suggesting a likely effect on the sensory profile. However, higher intensity aeration early in ferment was detrimental to wine quality with the appearance of elevated volatile acidity; thus, judicious air addition is advised during winemaking. Air addition is, therefore, a tool that winemakers may use to improve fermentation performance and shape yeast community structure in uninoculated white wines.

Supplementary Materials: The following are available online at https:/ / www.mdpi.com/article/10 .3390 / fermentation7020097/s1: Figure S1, Principal coordinates analysis (PCoA) for ferments from the 2019 (A) and 2020 (B) vintages, Table S1: Estimated total oxygen exposure, Table S2: Percentage of consumed sugar at each sampling point, Table S3: Abundance for fungal OTUs in 2019 wines, Table S4: Abundance for fungal OTUs in 2020 wines, Table S5: Distance-based redundancy analysis (DBRDA) of Bray distances for yeast communities (999 permutations), Table S6: Concentration of volatile compounds in 2019 wines, Table S7: Concentration of volatile compounds in 2019 wines. 
Author Contributions: Conceptualization, A.B. and S.S.; methodology, K.C., S.V.D.H., M.S. and C.V.; investigation, K.C., S.V.D.H., M.R., M.S. and C.V.; formal analysis, S.S., A.B. and C.V.; writingoriginal draft preparation, C.V.; writing-review and editing, all authors. All authors have read and agreed to the published version of the manuscript.

Funding: The AWRI is supported by Australia's grape growers and winemakers through their investment body Wine Australia with matching funds from the Australian Government.

Institutional Review Board Statement: Not applicable.

Informed Consent Statement: Not applicable.

Data Availability Statement: Raw reads are available from the BioProject website (accession number PRJNA727920).

Acknowledgments: The authors would like to thank Renata Kucera for helping with the oxygen data. The AWRI is a member of the Wine Innovation Cluster in Adelaide. Metabolomics Australia is funded through the Australian Government National Collaborative Research Infrastructure Strategy (NCRIS).

Conflicts of Interest: The authors declare no conflict of interest.

\section{References}

1. Jolly, N.P.; Varela, C.; Pretorius, I.S. Not your ordinary yeast: Non-Saccharomyces yeasts in wine production uncovered. FEMS Yeast Res. 2014, 14, 215-237. [CrossRef]

2. Medina, K.; Boido, E.; Farina, L.; Gioia, O.; Gomez, M.E.; Barquet, M.; Gaggero, C.; Dellacassa, E.; Carrau, F. Increased flavour diversity of Chardonnay wines by spontaneous fermentation and co-fermentation with Hanseniaspora vineae. Food Chem. 2013, 141, 2513-2521. [CrossRef]

3. Uzkuc, N.M.C.; Sisli, B.; Ay, M.; Togay, S.O.; Yuceer, Y.K.; Bayhan, A.; Toklucu, A.K. Effects of spontaneous fermentation on Karalahna and Cabernet Sauvignon young red wines: Volatile compounds, sensory profiles and identification of autochthonous yeasts. Eur. Food Res. Technol. 2020, 246, 81-92. [CrossRef]

4. Varela, C.; Siebert, T.; Cozzolino, D.; Rose, L.; McLean, H.; Henschke, P.A. Discovering a chemical basis for differentiating wines made by fermentation with 'wild' indigenous and inoculated yeasts: Role of yeast volatile compounds. Aust. J. Grape Wine Res. 2009, 15, 238-248. [CrossRef]

5. Fleet, G.H. Wine yeasts for the future. FEMS Yeast Res. 2008, 8, 979-995. [CrossRef] [PubMed]

6. Fleet, G.; Prakitchaiwattana, C.; Beh, S.; Heard, G. The yeast ecology of wine grapes. In Biodiversity and Biotechnology of Wine Yeast; Ciani, M., Ed.; Research Signpost: Kerala, India, 2002; pp. 1-17.

7. Heard, G. Novel yeasts in winemaking-looking to the future. Food Aust. 1999, 51, 347-352.

8. Romano, P.; Fiore, C.; Paraggio, M.; Caruso, M.; Capece, A. Function of yeast species and strains in wine flavour. Int. J. Food Microbiol. 2003, 86, 169-180. [CrossRef]

9. Beltran, G.; Torija, M.J.; Novo, M.; Ferrer, N.; Poblet, M.; Guillamon, J.M.; Rozes, N.; Mas, A. Analysis of yeast populations during alcoholic fermentation: A six year follow-up study. Syst. Appl. Microbiol. 2002, 25, 287-293. [CrossRef] [PubMed]

10. Combina, M.; Elia, A.; Mercado, L.; Catania, C.; Ganga, A.; Martinez, C. Dynamics of indigenous yeast populations during spontaneous fermentation of wines from Mendoza, Argentina. Int. J. Food Microbiol. 2005, 99, 237-243. [CrossRef]

11. Fleet, G.H.; Heard, G.M. Yeasts: Growth during fermentation. In Wine Microbiology and Biotechnology; Fleet, G.H., Ed.; Harwood Academic: Chur, Switzerland, 1993; pp. 27-54.

12. Fleet, G.H.; Lafonlafourcade, S.; Ribereaugayon, P. Evolution of yeasts and lactic acid bacteria during fermentation and storage of Bordeaux wines. Appl. Environ. Microbiol. 1984, 48, 1034-1038. [CrossRef]

13. Albertin, W.; Miot-Sertier, C.; Bely, M.; Marullo, P.; Coulon, J.; Moine, V.; Colonna-Ceccaldi, B.; Masneuf-Pomarede, I. Oenological prefermentation practices strongly impact yeast population dynamics and alcoholic fermentation kinetics in Chardonnay grape must. Int. J. Food Microbiol. 2014, 178, 87-97. [CrossRef] [PubMed]

14. Bagheri, B.; Bauer, F.F.; Setati, M.E. The diversity and dynamics of indigenous yeast communities in grape must from vineyards employing different agronomic practices and their influence on wine fermentation. S. Afr. J. Enol. Vitic. 2015, 36, 243-251. [CrossRef]

15. Bokulich, N.A.; Thorngate, J.H.; Richardson, P.M.; Mills, D.A. Microbial biogeography of wine grapes is conditioned by cultivar, vintage, and climate. Proc. Natl. Acad. Sci. USA 2014, 111, E139-E148. [CrossRef]

16. Morgan, S.C.; Scholl, C.M.; Benson, N.L.; Stone, M.L.; Durall, D.M. Sulfur dioxide addition at crush alters Saccharomyces cerevisiae strain composition in spontaneous fermentations at two Canadian wineries. Int. J. Food Microbiol. 2017, 244, 96-102. [CrossRef] [PubMed]

17. Morrison-Whittle, P.; Lee, S.A.; Goddard, M.R. Fungal communities are differentially affected by conventional and biodynamic agricultural management approaches in vineyard ecosystems. Agric. Ecosyst. Environ. 2017, 246, 306-313. [CrossRef]

18. Bagheri, B.; Bauer, F.F.; Cardinali, G.; Setati, M.E. Ecological interactions are a primary driver of population dynamics in wine yeast microbiota during fermentation. Sci. Rep. 2020, 10, 1-2. [CrossRef] 
19. Egli, C.M.; Edinger, W.D.; Mitrakul, C.M.; Henick-Kling, T. Dynamics of indigenous and inoculated yeast populations and their effect on the sensory character of Riesling and Chardonnay wines. J. Appl. Microbiol. 1998, 85, 779-789. [CrossRef] [PubMed]

20. Morgan, S.C.; Tantikachornkiat, M.; Scholl, C.M.; Benson, N.L.; Cliff, M.A.; Durall, D.M. The effect of sulfur dioxide addition at crush on the fungal and bacterial communities and the sensory attributes of Pinot gris wines. Int. J. Food Microbiol. 2019, 290, 1-14. [CrossRef]

21. Cuijvers, K.; Van den Heuvel, S.; Varela, C.; Rullo, M.; Solomon, M.; Schmidt, S.; Borneman, A. Alterations in yeast species composition of uninoculated wine ferments by the addition of sulphur dioxide. Fermentation 2020, 6, 62. [CrossRef]

22. Blateyron, L.; Sablayrolles, J. Stuck and slow fermentations in enology: Statistical study of causes and effectiveness of combined additions of oxygen and diammonium phosphate. J. Biosci. Bioeng. 2001, 91, 184-189. [CrossRef]

23. Fornairon-Bonnefond, C.; Aguera, E.; Deytieux, C.; Sablayrolles, J.M.; Salmon, J.M. Impact of oxygen addition during enological fermentation on sterol contents in yeast lees and their reactivity towards oxygen. J. Biosci. Bioeng. 2003, 95, 496-503. [CrossRef]

24. Larue, F.; Lafon-Lafourcade, S.; Ribéreau-Gayon, P. Relationship between the sterol content of yeast cells and their fermentation activity in grape must. Appl. Environ. Microbiol. 1980, 39, 808-811. [CrossRef]

25. Mauricio, J.C.; Moreno, J.; Zea, L.; Ortega, J.M.; Medina, M. The effects of grape must fermentation conditions on volatile alcohols and esters formed by Saccharomyces cerevisiae. J. Sci. Food Agric. 1997, 75, 155-160. [CrossRef]

26. Blateyron, L.; Aguera, E.; Dubois, C.; Gerland, C.; Sablayrolles, J.M. Control of oxygen additions during alcoholic fermentations. Vitic. Enol. Sci. 1998, 53, 131-135.

27. Sablayrolles, J.M.; Dubois, C.; Manginot, C.; Roustan, J.L.; Barre, P. Effectiveness of combined ammoniacal nitrogen and oxygen additions for completion of sluggish and stuck wine fermentations. J. Ferment. Bioeng. 1996, 82, 377-381. [CrossRef]

28. Delfini, C.; Conterno, L.; Giacosa, D.; Cocito, S.; Ravaglia, S.; Bardi, L. Influence of clarification and suspended solid contact on oxygen demand and long-chain fatty acid contents of free run, macerated and pressed grape musts, in relation to acetic acid production. Vitic. Enol. Sci. 1992, 47, 69-75.

29. Valero, E.; Moyano, L.; Millan, M.C.; Medina, M.; Ortega, J.M. Higher alcohols and esters production by Saccharomyces cerevisiae. Influence of the initial oxygenation of the grape must. Food Chem. 2002, 78, 57-61. [CrossRef]

30. Varela, C.; Torrea, D.; Schmidt, S.A.; Ancin-Azpilicueta, C.; Henschke, P.A. Effect of oxygen and lipid supplementation on the volatile composition of chemically defined medium and Chardonnay wine fermented with Saccharomyces cerevisiae. Food Chem. 2012, 135, 2863-2871. [CrossRef] [PubMed]

31. McRae, J.M.; Day, M.P.; Bindon, K.A.; Kassara, S.; Schmidt, S.A.; Schulkin, A.; Kolouchova, R.; Smith, P.A. Effect of early oxygen exposure on red wine colour and tannins. Tetrahedron 2015, 71, 3131-3137. [CrossRef]

32. Bekker, M.Z.; Day, M.P.; Holt, H.; Wilkes, E.; Smith, P.A. Effect of oxygen exposure during fermentation on volatile sulfur compounds in Shiraz wine and a comparison of strategies for remediation of reductive character. Aust. J. Grape Wine Res. 2016, 22, 24-35. [CrossRef]

33. Varela, C.; Pizarro, F.; Agosin, E. Biomass content governs fermentation rate in nitrogen-deficient wine musts. Appl. Environ. Microbiol. 2004, 70, 3392-3400. [CrossRef]

34. Bizaj, E.; Cordente, A.G.; Bellon, J.R.; Raspor, P.; Curtin, C.D.; Pretorius, I.S. A breeding strategy to harness flavor diversity of Saccharomyces interspecific hybrids and minimize hydrogen sulfide production. FEMS Yeast Res. 2012, 12, 456-465. [CrossRef]

35. Siebert, T.E.; Solomon, M.R.; Pollnitz, A.P.; Jeffery, D.W. Selective determination of volatile sulfur compounds in wine by gas chromatography with sulfur chemiluminescence detection. J. Agric. Food Chem. 2010, 58, 9454-9462. [CrossRef]

36. Bokulich, N.A.; Mills, D.A. Improved selection of internal transcribed spacer-specific primers enables quantitative, ultra-highthroughput profiling of fungal communities. Appl. Environ. Microbiol. 2013, 79, 2519-2526. [CrossRef]

37. Sternes, P.R.; Lee, D.; Kutyna, D.R.; Borneman, A.R. A combined meta-barcoding and shotgun metagenomic analysis of spontaneous wine fermentation. Gigascience 2017, 6, gix040. [CrossRef]

38. Bolger, A.M.; Lohse, M.; Usadel, B. Trimmomatic: A flexible trimmer for Illumina sequence data. Bioinformatics 2014, 30, 2114-2120. [CrossRef]

39. Martin, M. Cutadapt removes adapter sequences from high-throughput sequencing reads. EMBnet. J. 2011, 17, 10-12. [CrossRef]

40. Magoc, T.; Salzberg, S.L. FLASH: Fast length adjustment of short reads to improve genome assemblies. Bioinformatics 2011, 27, 2957-2963. [CrossRef]

41. Edgar, R.C. Search and clustering orders of magnitude faster than BLAST. Bioinformatics 2010, 26, 2460-2461. [CrossRef] [PubMed]

42. Mahe, F.; Rognes, T.; Quince, C.; de Vargas, C.; Dunthorn, M. Swarm: Robust and fast clustering method for amplicon-based studies. PeerJ 2014, 2, e593. [CrossRef]

43. Caporaso, J.G.; Kuczynski, J.; Stombaugh, J.; Bittinger, K.; Bushman, F.D.; Costello, E.K.; Fierer, N.; Pena, A.G.; Goodrich, J.K.; Gordon, J.I.; et al. QIIME allows analysis of high-throughput community sequencing data. Nat. Methods 2010, 7, 335-336. [CrossRef] [PubMed]

44. McMurdie, P.J.; Holmes, S. Phyloseq: An R package for reproducible interactive analysis and graphics of microbiome census data. PLoS ONE 2013, 8, e61217. [CrossRef]

45. Oksanen, J.; Blanchet, G.; Friendly, M.; Kindt, R.; Legendre, P.; McGlinn, D.; Minchin, P.; O’Hara, R.; Simpson, G.; Solymos, P.; et al. Vegan: Community Ecology Package. R Package Version 2.5.4. Available online: https:/ /CRAN.R-project.org/package=vegan (accessed on 30 June 2019). 
46. Lahti, L.; Shetty, S. Tools for Microbiome Analysis in R. Version 1.9.1. Available online: http://microbiome.github.com/ microbiome (accessed on 30 June 2019).

47. Wickham, H. Ggplot2: Elegant Graphics for Data Analysis; Springer: New York, NY, USA, 2009.

48. R Core Team. R: A Language and Environment for Statistical Computing. Available online: http://www.R-project.org/ (accessed on 3 March 2018).

49. De Mendiburu, F.; Yaseen, M. Agricolae: Statistical Procedures for Agricultural Research. Available online: https://myaseen208 .github.io/agricolae/https:/ / cran.r-project.org/package=agricolae (accessed on 12 November 2020).

50. Lê, S.; Josse, J.; Husson, F. FactoMineR: An R package for multivariate analysis. J. Stat. Softw. 2008, 25, 1-18. [CrossRef]

51. Dowle, M.; Srinivasan, A. Data. Table: Extension of 'Data.frame'. Available online: https: / /CRAN.R-project.org/package=data. table (accessed on 12 November 2020).

52. Liland, K.H.; Almøy, T.; Mevik, B.H. Optimal choice of baseline correction for multivariate calibration of spectra. Appl. Spectrosc. 2010, 64, 1007-1016. [CrossRef] [PubMed]

53. Denney, W.; Duvvuri, S.; Buckeridge, C. Simple, automatic noncompartmental analysis: The PKNCA R package. J. Pharm. Pharm. 2015, 42, 11-107.

54. Day, M.P.; Espinase Nandorfy, D.; Bekker, M.Z.; Bindon, K.A.; Solomon, M.; Smith, P.A.; Schmidt, S.A. Aeration of Vitis vinifera Shiraz fermentation and its effect on wine chemical composition and sensory attributes. Aust. J. Grape Wine Res. 2021. [CrossRef]

55. Day, M.P.; Schmidt, S.A.; Smith, P.A.; Wilkes, E.N. Use and impact of oxygen during winemaking. Aust. J. Grape Wine Res. 2015, 21, 693-704. [CrossRef]

56. Restrepo, S.; Espinoza, L.; Ceballos, A.; Urtubia, A. Production of fatty acids during alcoholic wine fermentation under selected temperature and aeration conditions. Am. J. Enol. Vitic. 2019, 70, 169-176. [CrossRef]

57. Yan, G.L.; Zhang, B.Q.; Joseph, L.; Waterhouse, A.L. Effects of initial oxygenation on chemical and aromatic composition of wine in mixed starters of Hanseniaspora vineae and Saccharomyces cerevisiae. Food Microbiol. 2020, 90, 103460. [CrossRef]

58. Englezos, V.; Cravero, F.; Torchio, F.; Rantsiou, K.; Ortiz-Julien, A.; Lambri, M.; Gerbi, V.; Rolle, L.; Cocolin, L. Oxygen availability and strain combination modulate yeast growth dynamics in mixed culture fermentations of grape must with Starmerella bacillaris and Saccharomyces cerevisiae. Food Microbiol. 2018, 69, 179-188. [CrossRef]

59. Hansen, E.H.; Nissen, P.; Sommer, P.; Nielsen, J.C.; Arneborg, N. The effect of oxygen on the survival of non-Saccharomyces yeasts during mixed culture fermentations of grape juice with Saccharomyces cerevisiae. J. Appl. Microbiol. 2001, 91, 541-547. [CrossRef]

60. Shekhawat, K.; Bauer, F.F.; Setati, M.E. Impact of oxygenation on the performance of three non-Saccharomyces yeasts in cofermentation with Saccharomyces cerevisiae. Appl. Microbiol. Biotechnol. 2017, 101, 2479-2491. [CrossRef] [PubMed]

61. Bagheri, B.; Bauer, F.F.; Setati, M.E. The impact of Saccharomyces cerevisiae on a wine yeast consortium in natural and inoculated fermentations. Front. Microbiol. 2017, 8, 1988. [CrossRef] [PubMed]

62. Wang, C.; Mas, A.; Esteve-Zarzoso, B. The Interaction between Saccharomyces cerevisiae and Non-Saccharomyces yeast during alcoholic fermentation is species and strain specific. Front. Microbiol. 2016, 7, 502. [CrossRef]

63. Ciani, M.; Beco, L.; Comitini, F. Fermentation behaviour and metabolic interactions of multistarter wine yeast fermentations. Int. J. Food Microbiol. 2006, 108, 239-245. [CrossRef]

64. Harle, O.; Legrand, J.; Tesniere, C.; Pradal, M.; Mouret, J.R.; Nidelet, T. Investigations of the mechanisms of interactions between four non-conventional species with Saccharomyces cerevisiae in oenological conditions. PLoS ONE 2020, 15, e0233285. [CrossRef]

65. Shekhawat, K.; Porter, T.J.; Bauer, F.F.; Setati, M.E. Employing oxygen pulses to modulate Lachancea thermotolerans-Saccharomyces cerevisiae Chardonnay fermentations. Ann. Microbiol. 2018, 68, 93-102. [CrossRef]

66. Bertrand, A.; Torresalegre, V. Influence of oxygen added to grape must on the synthesis of secondary products of the alcoholic fermentation. Sci. Des Aliment. 1984, 4, 45-64.

67. Farina, L.; Medina, K.; Urruty, M.; Boido, E.; Dellacassa, E.; Carrau, F. Redox effect on volatile compound formation in wine during fermentation by Saccharomyces cerevisiae. Food Chem. 2012, 134, 933-939. [CrossRef]

68. Plata, C.; Mauricio, J.C.; Millan, C.; Ortega, J.M. Influence of glucose and oxygen on the production of ethyl acetate and isoamyl acetate by a Saccharomyces cerevisiae strain during alcoholic fermentation. World J. Microbiol. Biotechnol. 2005, 21, 115-121. [CrossRef]

69. Tronchoni, J.; Curiel, J.A.; Saenz-Navajas, M.P.; Morales, P.; de-la-Fuente-Blanco, A.; Fernandez-Zurbano, P.; Ferreira, V.; Gonzalez, R. Aroma profiling of an aerated fermentation of natural grape must with selected yeast strains at pilot scale. Food Microbiol. 2018, 70, 214-223. [CrossRef] [PubMed] 